\title{
Malignant Pleural Effusion from Metastatic Prostate Cancer: A Case Report with Unusual Cytologic Findings
}

Jinyoung Jeon · Tae-Jung Kim ${ }^{1}$ Hong Sik Park · Kyo-Young Lee

Department of Hospital Pathology, Seoul St. Mary's Hospital, Seoul; 'Department of Hospital Pathology, Yeouido St. Mary's Hospital, College of Medicine, The Catholic University of Korea, Seoul, Korea

Received: February 20, 2018

Revised: April 24, 2018

Accepted: May 8, 2018

\section{Corresponding Author}

Kyo-Young Lee, MD, PhD

Department of Hospital Pathology, Seoul St. Mary's Hospital, College of Medicine, The Catholic

University of Korea, 222 Banpo-daero, Seocho-gu,

Seoul 06591, Korea

Tel: +82-2-2258-1618

Fax: +82-2-2258-1627

E-mail: leekyoyo@catholic.ac.kr
We present a case of 55-year-old man who complained of dyspnea and sputum for a month. He was an ex-smoker with a history of prostate cancer and pulmonary tuberculosis. Chest radiographs revealed bilateral pleural effusions of a small to moderate amount. Pigtail catheters were inserted for drainage. The pleural fluid consisted of large clusters and tightly cohesive groups of malignant cells, which however could not be ascribed to prostate cancer with certainty. We performed immunocytochemical panel studies to determine the origin of cancer metastasis. The immunostaining results were positive for prostate-specific antigen, alpha-methylacyl-coenzyme A racemase, and Nkx 3.1, consistent with prostate cancer. Pleural effusion associated with prostate cancer is rare. To our knowledge, this is the first case report in Korea to describe cytologic features of malignant pleural effusion associated with prostate cancer.

Key Words: Prostatic neoplasms; Neoplasm metastasis; Pleural effusion, malignant
Malignant pleural effusion (MPE) is diagnosed by identifying malignant cells in pleural fluid or on pleural biopsy. ${ }^{1,2}$ Metastatic adenocarcinoma is the most commonly found type of cancer in MPE; the most common causes of MPE are lung cancer, breast cancer, lymphoma, ovarian and gastric cancer in the descending order of occurrence. ${ }^{3}$ Prostate cancer can metastasize to nearly every organ, but most frequently to bones and regional lymph nodes. The most frequent sites of atypical metastases are reported to be the lungs and pleura (40\%), liver (37\%), supradiaphragmatic lymph nodes (34\%), and adrenal glands (15\%)., Regardless of the location, whether pleural, pericardial or ascitic, malignant effusions are rather infrequent complication of prostate cancer. ${ }^{6-11}$ There are few cytologic findings of pleural effusion due to prostate cancer described in the literature. Herein, we report a rare case of pleural effusion due to prostate cancer, showing unusually large cell-clusters.

\section{CASE REPORT}

A 55-year-old man was referred to the pulmonary clinic due to dyspnea and sputum for a month. He was an ex-smoker with a 45 pack-year history and had tuberculosis 25 years ago. Two years prior, the patient presented with a low back pain and anal incontinence. The tumor appeared to replace most of the prostate and spread to perirectal area and bilateral pelvic wall on computed tomography (CT) (Fig. 1A). Extensive pelvic lymphadenopathy and bone metastasis of the 11th thoracic vertebra were also found. He underwent a palliative transurethral resection of the prostate (TURP) and was diagnosed with prostate cancer of Gleason score $9(4+5)$ on pathologic examination. He started receiving radiation therapy while taking leuprorelin, a gonadotropin-releasing hormone agonist. The prostate-specific antigen (PSA) levels dropped from 78.54 to $0.2 \mathrm{ng} / \mathrm{mL}$ and the androgen levels reached within castration concentrations (testosterone 0.13 $\mathrm{ng} / \mathrm{dL}$, free testosterone $0.58 \mathrm{ng} / \mathrm{dL}$ ) for a year.

On chest radiographs, bilateral pleural effusions of a small to moderate amount were observed (Fig. 1B), with a larger amount on the right side (Fig. 1C). No mass-like lesion was found on thoracic CT scan. Bone scans showed newly noted multifocal uptakes in skull, rib cage, sacrum, pelvic bones, humeri, and 
femurs. For reliable diagnosis and appropriate management, ultrasound-guided percutaneous pigtail catheters were inserted. The drained pleural fluid was turbid yellow with glucose 94 $\mathrm{mg} / \mathrm{dL}$, protein $4.4 \mathrm{~g} / \mathrm{dL}$, triglyceride $13 \mathrm{mg} / \mathrm{dL}$, lactate dehydrogenase 1,113 U/L, and adenosine deaminase $17.1 \mathrm{IU} / \mathrm{L}$. Its differential count was $7 \%$ lymphocytes, $41 \%$ macrophages, $5 \%$ mesothelial cells, and $47 \%$ malignant cells. PSA in pleural fluid and concomitant serum PSA were 21.50 and $44.71 \mathrm{ng} / \mathrm{mL}$ respectively.

The pleural fluid was prepared with routine conventional smear. The Papanicolaou stained smears showed groups of neoplastic cells arranged in large cell-clusters (Fig. 2A). Most of them formed large three-dimensional balls without glandular lumen (Fig. 2B), and they consisted of medium sized round to ovoid cells showing coarse, finely granular and vesicular chromatin. Most tumor cells showed smooth nuclear contours with large prominent nucleoli, but some showed irregular nuclear borders. They had hyperchromatic nuclei with a high nuclear to cytoplasmic (N/C) ratio (Fig. 2C). Nuclear pleomorphism was minimal to mild and mitosis was hardly found (less than 1/10 high-power field). The architectural and cytologic features were mostly similar on cell block, but a few glandular lumens were found. The tumor cells were in tightly cohesive groups without lumen (Fig. 2D). A very few of them had glandular lumen-like space with central necrosis (Fig. 2E). They had pale eosinophilic to clear cytoplasm, and the amount of cytoplasm was small to moderate. Based on these findings, the tumor cells were taken to be poorly differentiated carcinoma of unknown origin.

Immunocytochemical panel studies were performed on the cell block to determine the origin of cancer metastasis. The tumor cells were immunopositive for PSA (Fig. 2F), alpha-methylacylcoenzyme A racemase (AMACR) (Fig. 2G), and Nkx 3.1 (Fig. $2 \mathrm{H})$. They showed negative immunoreactivity for $\mathrm{P} 40$, cytokeratin 5/6 (Fig. 2I), thyroid transcription factor- 1 and gross cystic disease fluid protein.

The patient was finally diagnosed with metastatic castration resistant prostate cancer. He was then treated with a second-line chemotherapeutic agent, biweekly docetaxel and oral dexamethasone.

This study was approved by the Institutional Review Board (IRB) of The Catholic University of Korea, Seoul St. Mary's Hospital (KC17ZESI0451) and was performed in accordance with the principles of the Declaration of Helsinki. The patient informed consent was waived.

\section{DISCUSSION}

Secondary pleural effusion from prostate cancer is a rare clinical manifestation. Moreover, it is even more rare to find malignant cells in pleural fluid on microscopic examination. So far, we have had a little more than 20 cases and fewer than 10 papers on MPE due to prostate cancer. Two of them are review papers including 10 and six cases, respectively (Table 1). ${ }^{12,13}$ According to the literature, MPE caused by prostate cancer share several common characteristics: the patients are usually in high stage at the time of diagnosis, and the tumors are of high grade and unresectable. ${ }^{13}$ the tumor cells have round to oval nuclei with large prominent nucleoli and scant cytoplasm: they show high N/C ratio, nuclear hyperchromasia and relatively smooth nuclear borders. Most tumor cells appear as isolated cells or in small, loosely cohesive
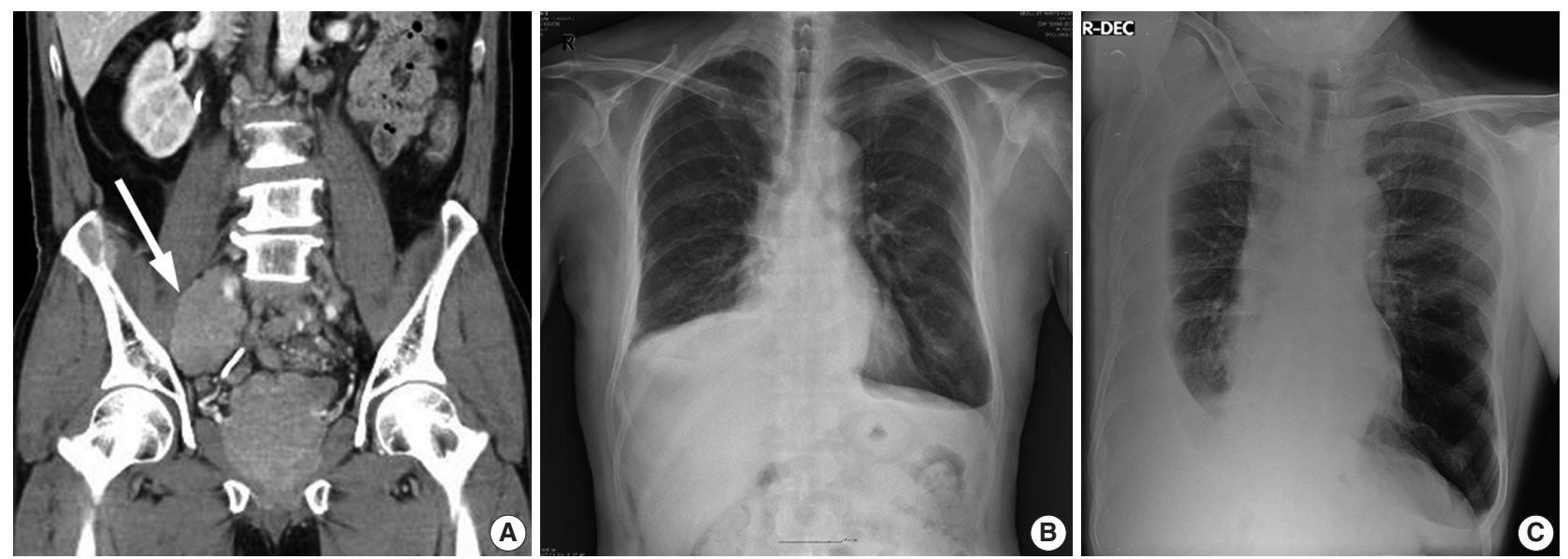

Fig. 1. Radiologic findings of the patient. (A) The tumor appears to replace most of the prostate and spread to perirectal area and bilateral pelvic wall on contrast-enhanced computed tomography. Extensive regional lymphadenopathy is observed (arrow). The chest X-ray reveals bilateral pleural effusions of a small to moderate amount (B) with a larger amount on the right side (C). 

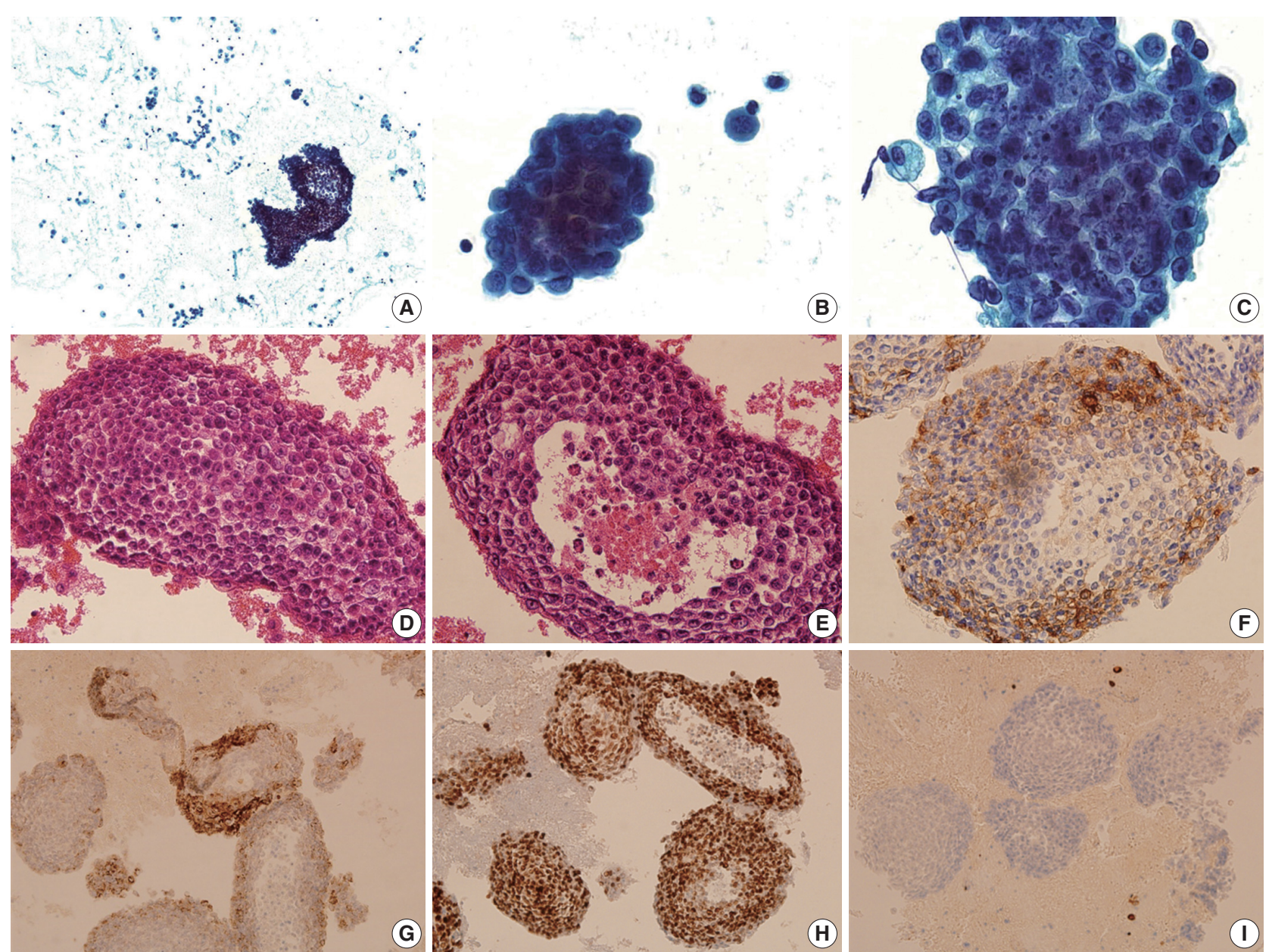

Fig. 2. Cytologic features of Papanicolaou smears $(A-C)$, the cell block (D-F) and the result of immunocytochemical staining (G-I). (A) It shows a sheet-like cell group. (B) A large cell-cluster is noted, forming three-dimensional ball. Hyperchromatic nuclei and high nuclear to cytoplasmic ratio are also observed. (C) The tumor cells have coarse, finely granular and vesicular chromatin. (D) The majority are in tightly cohesive groups of cells. (E) Some groups have the glandular lumen-like structure with central necrosis. Tumor cells are immunopositive for prostate-specific antigen (F), alpha-methylacyl-coenzyme A racemase (G), and Nkx $3.1(\mathrm{H})$. (I) They show negative immunoreactivity for cytokeratin 5/6.

groups. ${ }^{12,13}$ There was only one exception to this consistent cytologic pattern, and that case showed the tumor cells arranged in large tightly cohesive balls. ${ }^{13}$ Our case shared those unusual cytologic features, showing cytologic patterns that are more commonly seen in breast cancer. Three dimensional cell balls of various sizes with smooth outer contours, referred to as cannon balls, are well known as one of the common characteristics of malignant effusion from breast adenocarcinoma. The cytomorphologic pattern of malignant mesothelioma varies widely, which is well known to mimic other malignancies, the most common being adenocarcinoma. It should be kept in mind that the morphologic overlap may preclude an accurate identification of poorly differentiated metastatic adenocarcinoma.

The differential diagnosis included metastatic adenocarcinomas from the prostate, lung, breast, gastrointestinal tract, and thyroid gland. Prostate origin was most suspected due to the patient's past history. Metastatic non-keratinizing squamous cell carcinoma and primary malignant mesothelioma were also on the list to be excluded. Poorly differentiated squamous cell carcinoma in pleural effusion may resemble the cytomorphology of adenocarcinoma, however, most have been reported to have metastasized from the head and neck area or genital organs. Also, malignant mesothelioma was considered as the least likely because there was no mass-like lesion on imaging studies.

Hematoxylin and eosin stained sections of TURP specimen of the primary tumor were available for histological review, and were compared with the cytology. The primary tumor was a poorly differentiated carcinoma (Fig. 3A). Lymphovascular invasion 
Table 1. Reported cases of malignant pleural effusion from prostate cancer

\begin{tabular}{|c|c|c|c|c|c|c|c|c|c|}
\hline \multirow{2}{*}{ Author } & \multirow{2}{*}{ Year } & \multirow{2}{*}{$\begin{array}{l}\text { No. of } \\
\text { cases }\end{array}$} & \multirow{2}{*}{ Age (yr) } & \multirow{2}{*}{ Histologic differentiation } & \multirow{2}{*}{$\begin{array}{l}\text { Effusion } \\
\text { side }\end{array}$} & \multirow{2}{*}{$\begin{array}{l}\text { Intrathoracic cavity } \\
\text { involvement }\end{array}$} & \multirow{2}{*}{$\begin{array}{l}\text { Pleural fluid } \\
\text { cytology }\end{array}$} & \multicolumn{2}{|c|}{ PSA (ng/mL) } \\
\hline & & & & & & & & Fluid & Serum \\
\hline Knight et al. ${ }^{9}$ & 2014 & 1 & 73 & NS & Bilateral & Pleura with lung entrapment & Atypical cells & 1,619 & 2,540 \\
\hline Bajpai et al. ${ }^{7}$ & 2014 & 1 & 84 & GS 6 & Right & Isolated PE & Adenocarcinoma & NS & $>148$ \\
\hline Mai et al..$^{12}$ & 2007 & 6 & $77 \pm 8$ & GS $8.1 \pm 1.5$ & NS & NS & Adenocarcinoma & NS & $4.1 \pm 2.3$ \\
\hline Renshaw et al. ${ }^{13}$ & 1996 & 10 & $\begin{array}{l}\text { Mean } \\
67\end{array}$ & $\begin{array}{l}\text { GS } 7(n=4) \text {, GS } 8(n=1), \\
\text { GS } 9(n=2) \text {, anaplastic } \\
\text { small cell carcinoma }(n=3)\end{array}$ & NS & $\begin{array}{l}\text { Lung }(n=1) \text {, pleura }(n=1) \\
\text { both lung and pleura }(n=2)\end{array}$ & Malignant cells & NS & NS \\
\hline Carrascosa et al..$^{14}$ & 1994 & 1 & 73 & NS & Right & Suspected PLC & Adenocarcinoma & NS & 197 \\
\hline Shimizu et al..$^{15}$ & 1993 & 1 & 65 & Poorly differentiated & Bilateral & Lung, PLC & Adenocarcinoma & NS & 292 \\
\hline \multirow[t]{2}{*}{ Mestitz et al. ${ }^{16}$} & 1989 & 2 & 67 & Poorly differentiated & Bilateral & Lung, PLC, mediastinal LAP & Adenocarcinoma & NS & NS \\
\hline & & & 69 & NS & Right & Isolated PE & Adenocarcinoma & NS & NS \\
\hline
\end{tabular}

PSA, prostate-specific antigen; NS, not stated; GS, Gleason score; PE, pleural effusion; PLC, pulmonary lymphangitis carcinomatosa; LAP, lymphadenopathy.
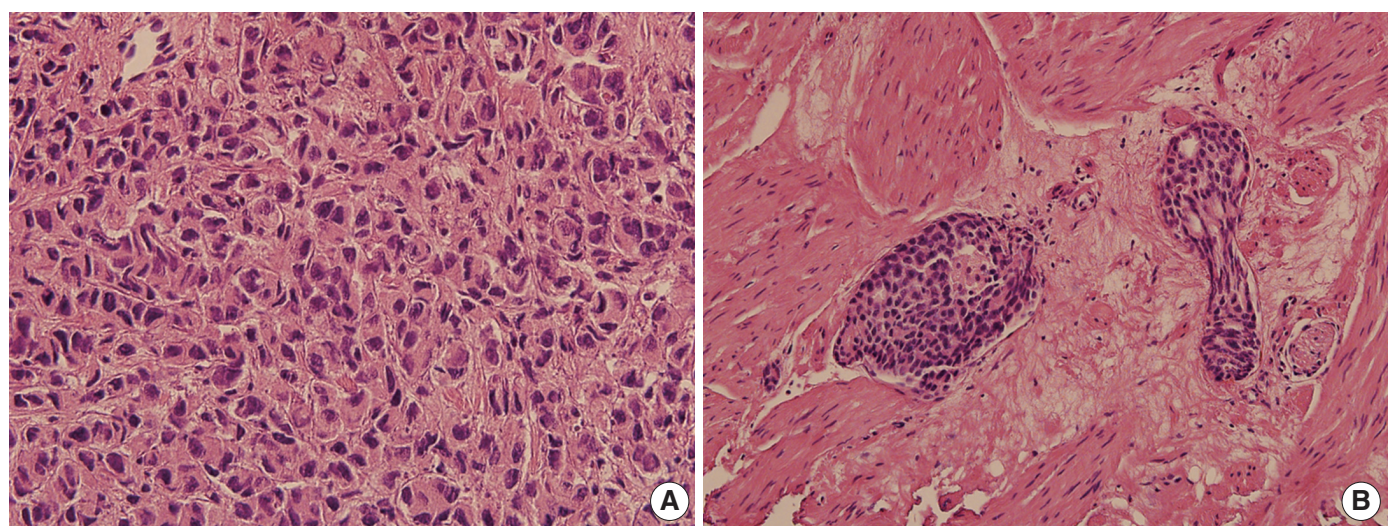

Fig. 3. The histological characteristics of transurethral resection of the prostate specimen. (A) The hematoxylin and eosin stained section shows a poorly differentiated carcinoma. (B) Lymphovascular invasion is observed with the tumor emboli forming well-demarcated ovoid masses.

was noted with the tumor emboli forming well-demarcated ovoid masses, usually in solid or cribriform architecture (Fig. 3B). These histologic features correlated well with the cytologic findings of pleural fluid. Since prostate cancer is famous for its various combinations of Gleason scores, it may not be surprising that the cytologic features also vary. Immunocytochemical staining is useful when cytologic findings are challenging. PSA is the most widely used biomarker for prostate cancer screening and treatment monitoring. Measurement of PSA in the pleural fluid is a useful adjunct test in the diagnosis of metastatic prostate cancer. However, immunocytochemical study of PSA displays negative, weak or focal staining in poorly differentiated carcinoma and in patients with prior hormone and/or radiation therapy. ${ }^{12,13}$ As such, we recommend to use other prostatic markers, such as prostate alkaline phosphatase, AMACR, and Nkx 3.1 in combination with PSA.

In summary, we herein reported a rare case of MPE from prostate cancer, showing unusual cytologic characteristics that may require challenging differential diagnosis.

\section{ORCID}

Tae-Jung Kim: https://orcid.org/0000-0003-3140-3681

Kyo-Young Lee: https://orcid.org/0000-0001-9954-8583

\section{Conflicts of Interest}

No potential conflict of interest relevant to this article was reported.

\section{REFERENCES}

1. Egan AM, McPhillips D, Sarkar S, Breen DP. Malignant pleural effusion. QJM 2014; 107: 179-84.

2. Thomas JM, Musani AI. Malignant pleural effusions: a review. Clin Chest Med 2013; 34: 459-71.

3. Lim MH, Garrettc J, Mowlem L, Yap E. Diagnosing malignant 
pleural effusions: how do we compare? N Z Med J 2013; 126: 42-8.

4. Bubendorf L, Schopfer A, Wagner U, et al. Metastatic patterns of prostate cancer: an autopsy study of 1,589 patients. Hum Pathol 2000; 31: 578-83.

5. Vinjamoori AH, Jagannathan JP, Shinagare AB, et al. Atypical metastases from prostate cancer: 10-year experience at a single institution. AJR Am J Roentgenol 2012; 199: 367-72.

6. Ani I, Costaldi M, Abouassaly R. Metastatic prostate cancer with malignant ascites: a case report and literature review. Can Urol Assoc J 2013; 7: E248-50.

7. Bajpai PA, Joshi P, Joseph D, Bajpai A. A case of recurrent massive right sided pleural effusion-an unusual presentation of carcinoma prostate. Lung India 2014; 31: 423-4.

8. dos Santos VM, Zembrzuski MM, Gouvea IP, Nery NS, dos Santos LA. Massive pleural effusion due to metastasis of prostate cancer. West Indian Med J 2011; 60: 690-3.

9. Knight JC, Ray MA, Benzaquen S. Malignant pleural effusion from prostate adenocarcinoma. Respir Med Case Rep 2014; 13: 24-5.

10. Saif MW. Malignant ascites associated with carcinoma of the pros- tate. J Appl Res 2005; 5: 305-11.

11. Saif MW, Figg WD, Hewitt S, Brosky K, Reed E, Dahut W. Malignant ascites as only manifestation of metastatic prostate cancer. Prostate Cancer Prostatic Dis 1999; 2: 290-3.

12. Mai KT, Roustan Delatour NL, Assiri A, Al-Maghrabi H. Secondary prostatic adenocarcinoma: a cytopathological study of 50 cases. Diagn Cytopathol 2007; 35: 91-5.

13. Renshaw AA, Nappi D, Cibas ES. Cytology of metastatic adenocarcinoma of the prostate in pleural effusions. Diagn Cytopathol 1996; 15: 103-7.

14. Carrascosa M, Perez-Castrillon JL, Mendez MA, Cillero L, Valle R. Malignant pleural effusion from prostatic adenocarcinoma resolved with hormonal therapy. Chest 1994; 105: 1577-8.

15. Shimizu T, Shibata Y, Uchida T, Satoh J. Severe flare-up in a prostate cancer patient treated with luteinizing hormone-releasing hormone analogue depot. Hinyokika Kiyo 1993; 39: 953-5.

16. Mestitz H, Pierce RJ, Holmes PW. Intrathoracic manifestations of disseminated prostatic adenocarcinoma. Respir Med 1989; 83: 161-6. 